\title{
Direito a saúde e a dignidade da pessoa humana: acesso a medicamentos e a visão das farmacêuticas
}

\author{
David Augusto Fernandes ${ }^{1}$
}

\begin{abstract}
Resumo
Apesar de estarmos no século XXI, ainda não se tem proporcionado as todas as pessoas, principalmente àqueles mais necessitados, o pleno direito de acesso aos medicamentos imprescindíveis, fato que lhes afeta a dignidade da pessoa humana (DPH). Este estudo objetiva enfatizar esse direito para essa camada populacional, fator importante para sua sobrevivência, dentro da meta dos Objetivos de Desenvolvimento Sustentável (ODS), da ONU, a serem alcançados até 2030. A problemática do estudo questiona os inibidores que inviabilizam esse direito de ser efetivado, apesar de a Constituição Brasileira e os organismos internacionais o assegurarem. A metodologia aplicada é a pesquisa bibliográfica e seu resultado constata que a DPH ainda não é oferecida a essas pessoas, devido à falta de política governamental rígida e à falta de adequação das farmacêuticas. As considerações finais reúnem os comentários do autor sobre a matéria.
\end{abstract}

Palavras-chave: medicamentos; saúde; farmacêuticas.

\section{Right to health and dignity of the human person: access to medicines and the vision of pharmaceuticals}

\begin{abstract}
Despite the fact that we are in the $21^{\text {st }}$ century, not all people, especially those most in need, have yet been given the full right of access to essential medicines, a fact that affects the dignity of the human person (DPH). This study aims to emphasize this right for this population strand, an important factor for their survival, within the goal of the UN Sustainable Development Goals (SDGs), to be achieved by 2030. The study's problematic questions the inhibitors that prevent this right to effective, despite the fact that the Brazilian Constitution and international organizations guarantee it. The applied methodology is bibliographic research and its result shows that DPH is not yet offered to these people, due to the lack of rigid government policy and the lack of adequacy of pharmaceutical companies. Final considerations bring together the author's comments on the matter.
\end{abstract}

Keywords: medicines; health; pharmaceutical companies.

\footnotetext{
${ }^{1}$ Pós-doutor em Democracia e Direitos Humanos pela Universidade de Coimbra/Portugal, Doutor e Mestre em Direito. Professor Adjunto do Curso de Direito da UFF/ICM/MDI. Docente dos Cursos de Especialização em Gestão Pública, Gestão Pública Municipal e Gestão em Saúde Pública, na modalidade de Ensino à Distância, ofertadas pela Universidade Federal Fluminense através do Consórcio CEDERJ e da Universidade Aberta do Brasil (UAB). CV: http://lattes.cnpq.br /8477467816197173. E-mail:davidaf@id.uff.br.
} 


\section{INTRODUÇÃO}

Calcada na Declaração Universal dos Direitos Humanos, a Organização das Nações Unidas (ONU) configurou os dezessete Objetivos de Desenvolvimento Sustentável (ODS) ${ }^{2}$ a serem alcançados até 2030. Vale ressalvar que em 2000 foram estipulados os Objetivos do Desenvolvimento do Milênio (ODM), prevendo, em seu oitavo objetivo ${ }^{3}$, o acesso a medicamentos essenciais nos países em desenvolvimento. Apesar de sua importância para a higidez, especialmente das populações mais carentes, tal objetivo não foi alcançado.

Entre os dias 25 a 27 de setembro de 2015, em reunião na sede da ONU, em Nova York, seus membros retornaram ao tema, para delinear os novos Objetivos de Desenvolvimento Sustentável Globais (ODS), no sentido de serem alcançados até 2030, mantendo entre eles o Objetivo $3^{4}$. Por meio desse Objetivo busca-se proporcionar acesso a medicamentos, com a garantia de que todos os seres humanos possam alcançar seu potencial em dignidade e igualdade, em ambiente saudável. Propõe-se que tal prerrogativa seja compartilhada por todos os seres humanos, conforme explicitado no parágrafo 26 , no qual se manifesta preocupação com a saúde de todos, a ser alcançada, inclusive, mediante o fornecimento de medicamentos.

Diante desses pressupostos, o presente trabalho objetiva determinar os possíveis impedimentos para que a clientela a ser enfocada na pesquisa ora desenvolvida não obtivesse acesso a medicamentos para tratar suas enfermidades, apesar de o objetivo da ONU compor o regramento interno contido na Constituição Federal. Se forem detectados esses impedimentos, busca-se identificar seu impacto no ambiente social e cultural.

A metodologia utilizada para a efetivação do trabalho foi a pesquisa bibliográfica, desenvolvida com base em livros, artigos científicos, legislação e meio eletrônico ligados ao tema em comento.

O principal problema que motivou a realização da pesquisa foi a constatação empírica, na realidade brasileira, da dificuldade de as pessoas com baixo poder aquisitivo obterem os medicamentos essenciais ao tratamento de suas enfermidades. Verifica-se, a priori, que tal

\footnotetext{
${ }^{2}$ Esses objetivos emergem dos estudos que a ONU realiza há décadas e que já foram apresentados em várias conferências, tais como Estocolmo (1972), Rio de Janeiro (1992), Johanesburgo (2002) e Rio+20 (2012), mas até o início da segunda década do século XXI não foram alcançados.

${ }^{3}$ Objetivo 8 da ODM. Estabelecer uma parceria global para o desenvolvimento.

Objetivos do Desenvolvimento do Milênio (ODM), em parceria com a indústria farmacêutica, prover acesso a medicamentos essenciais nos países em desenvolvimento.

${ }^{4}$ Objetivo 3 da ODS. Assegurar uma vida saudável e promover o bem-estar para todos, em todas as idades.

Atingir a cobertura universal de saúde, incluindo a proteção do risco financeiro, o acesso a serviços de saúde essências de qualidade e o acesso a medicamentos e vacinas essenciais.

3.b Apoiar a pesquisa e o desenvolvimento de vacinas e medicamentos para as doenças transmissíveis e não transmissíveis, que afetam principalmente os países em desenvolvimento, proporcionar o acesso a medicamentos e vacinas essenciais a preços acessíveis, de acordo com a Declaração de Doha sobre o Acordo TRIPS e Saúde Pública, que afirma o direito dos países em desenvolvimento de utilizarem plenamente as disposições de Acordo sobre os Aspectos dos Direitos de Propriedade Intelectual Relacionados ao Comércio (TRIPS, na sigla em inglês) sobre flexibilidades para proteger a saúde pública e, em particular, proporcionar acesso a medicamento para todos.
} 
situação afeta sua dignidade humana. Portanto, cabe determinar-se o fato gerador que vem causando esses impedimentos.

A escolha do tema enfocado na presente pesquisa justifica-se plenamente pela gravidade do problema que afeta camada considerável da população brasileira, merecedora de um olhar apurado, em sentido amplo, dos órgãos do Estado. É imperioso saber qual a resposta a ser dada pelo poder público a essas pessoas, de forma concreta e eficaz. Alia-se à seriedade de tal proposta o fato de que o descumprimento de tal norma afeta a dignidade da pessoa humana (DPH), inibindo sua inclusão no ambiente social em que está circunscrita.

Para abranger convenientemente as questões levantadas, aborda-se preliminarmente a DPH e sua afetação pelo não recebimento de medicamentos necessários ao seu tratamento. Em seguida, são enfocadas as políticas públicas voltadas para a área de saúde. Prosseguindo, focalizam-se o Sistema de Saúde brasileiro e o fornecimento de medicamentos às pessoas debilitadas socialmente e são expostas as obrigações pertinentes ao Estado que abrangem a área em estudo. A partir daí, já se torna possível discutir o acesso a medicamentos e o papel das indústrias farmacêuticas nesse sentido. Durante as considerações finais, são manifestadas as críticas gerais sobre este importante tema.

\section{A DIGNIDADE DA PESSOA HUMANA}

Para Luís Roberto Barroso, a dignidade da pessoa humana (DPH), na acepção contemporânea, tem origem religiosa, bíblica: o homem feito à imagem e semelhança de Deus. Com o Iluminismo e a centralidade do homem, ela migra para a filosofia, tendo por fundamento a razão, a capacidade de valoração moral e autodeterminação do indivíduo (BARROSO, 2010).

No século XVI, o posicionamento de teólogos espanhóis os levava a reconhecer os direitos naturais aos indivíduos, deduzidos do direito natural e tidos como expressão da liberdade e DPH, além de servirem de inspiração ao humanismo racionalista de Hugo Grócio. Nesse mesmo período, em 1589, o jus philosophus Hugo Donellus ensinava a seus discípulos que o direito à personalidade englobava o direito à vida, à personalidade corporal e à imagem, não podendo o primeiro ser dissociado da saúde (SARLET, 2004). Nesse sentido, Consuelo Cuesta Sanz (1998, p. 291) salienta o seguinte:

[...] a preocupação pelo comércio foi o motivo principal para convocar uma Primeira Conferência Sanitária Internacional, em 1851, em que 12 países firmaram uma convenção internacional sobre a quarentena contra a cólera, a peste e a febre amarela.

Com o passar dos séculos houve a consolidação de tal pensamento e sua inclusão em várias constituições dos séculos XVIII e XIX. Já a segunda metade do século XIX trouxe, com o desenvolvimento econômico, a consciência de que a saúde passou a ser considerada elemento essencial ao progresso social econômico e incluída como direito de todo o indivíduo. No início 
da década de 1940, a saúde já não era considerada como ausência de enfermidade, mas sim um bem em si mesmo, do qual se manifestava legítimo e profundamente justo beneficiar, com a mobilização dos recursos econômicos disponíveis em qualquer parte onde se encontrassem (SANZ,1998).

Ao término da Segunda Guerra Mundial, a ideia de DPH migra paulatinamente para o mundo jurídico, em razão de dois movimentos. O primeiro foi o surgimento de uma cultura pós-positivista, que reaproximou o Direito da filosofia moral e da filosofia política, atenuando a separação radical imposta pelo positivismo normativista. O segundo consistiu na inclusão da dignidade da pessoa humana em diferentes documentos internacionais e constituições de Estados democráticos. Convertida em conceito jurídico, a dificuldade atual está em dar a ela conteúdo mínimo que a torne uma categoria operacional e útil, tanto na prática doméstica de cada país, quanto no discurso transnacional (BARROSO, 2010, p. 14).

Somente após a Segunda Guerra Mundial, o ordenamento internacional passou a considerar a DPH como sendo o acesso à saúde um direito humano fundamental, mediante o qual cada cidadão deveria ter seus direitos respeitados pelo Estado. Assim, propicia que cada indivíduo tenha assegurada sua dignidade de pessoa humana, conforme enunciado pela primeira vez no preâmbulo da Constituição da Organização Mundial da Saúde e sucessivamente proclamado na Declaração Universal dos Direitos Humanos das Nações Unidas, em seu artigo 25. Portanto, esse direito tardou mais de meio século para afirmar-se como direito fundamental internacionalmente protegido (NEGRI, 2010).

No transcurso do século XX a DPH se torna um objetivo político, um fim a ser buscado pelo Estado e pela sociedade (BARROSO, 2010). O reconhecimento deste direito é conquista sociocultural bastante recente, cujo conteúdo foi cunhado há aproximadamente setenta anos pela comunidade internacional, assim como previsto em quase todas as constituições modernas no mundo, no sentido de se reconhecer a saúde como Direito Humano Fundamental. Está posto que não deva haver por parte dos Estados qualquer ato inibitório a colocar em perigo a saúde das pessoas, mas sim realizar todos os esforços para sua preservação (SANZ,1998).

Conforme leciona Ricardo Lobo Torres (1999, p. 138), está também incluído nessa linha de proteção à saúde o mínimo existencial (ME), compreendido como direito às condições mínimas de existência humana digna que não pode ser objeto de intervenção do Estado e que ainda exige prestações estatais positivas. O mínimo existencial, primariamente, está direcionado à liberdade e à democracia, não devendo ficar restrito a esse direcionamento, pois as condições básicas de vida devem ser asseguradas, de forma a atender aqueles que delas necessitam, conduzindo, também, à saúde para a vida plena e satisfatória.

O tema do conteúdo do ME é complexo e a primeira observação importante a se fazer é no sentido de existirem variações socioculturais significativas em relação ao concebido como necessidades básicas. Sociedades diferentes tendem a valorar de modo muito distinto determinados bens, de modo que o acesso a eles pode-se afigurar essencial para a vida digna das pessoas em algumas dessas sociedades e não em outras. Entretanto, parece inquestionável 
a existência de necessidades materiais decorrentes da própria natureza humana, como o acesso à saúde. E, para que tal ocorra, existe a necessidade de se produzir meios para o acesso aos medicamentos ser facilitado a todas as pessoas necessitadas (SARMENTO, 2016, p. 214-215). No próximo tópico se discute como tal acesso pode ser viabilizado.

\section{POLÍTICAS PÚBLICAS}

$\mathrm{Na}$ contemporaneidade, o Estado se destaca em relação a outros atores no estabelecimento de políticas públicas. A centralidade atual do Estado na definição e no estabelecimento de políticas públicas é consequência dos seguintes fatores principais: a) sua elaboração é uma das razões centrais do nascimento e da existência do Estado moderno; b) o Estado detém o monopólio do uso da força legitima e isso lhe dá superioridade objetiva com relação a outros atores; c) o Estado moderno controla grande parte dos recursos nacionais e, por isso, consegue elaborar políticas robustas temporal e espacialmente (SECCHI, 2016).

O legislador constituinte foi pródigo em inserir no artigo $5^{\circ}$, da Carta Magna vigente, o direito à vida, à liberdade e à igualdade, assim como aqueles coligados a esses, e todos, em conjunto, circundam o principal deles: a vida humana. Para esses direitos serem convenientemente observados, se faz necessário proporcionar ao ser humano o pleno atendimento na preservação de sua saúde, com o fornecimento de medicamentos para se restabelecer quando for o caso. Tal providência implica haver o conjunto de decisões, planos, metas e ações governamentais direcionadas para a resolução do problema de interesse de cada pessoa afetada pela falta de acesso aos medicamentos (SÉGUIN, 20025 ; BRASIL, 19886 ${ }^{6}$.

As políticas públicas são o conjunto de programas, ações e decisões tomadas pelos governos, sejam na esfera federal, estadual ou municipal com a participação, direta ou indireta, de entes públicos ou privados, objetivando alcançar o atendimento populacional de uma determinada área (SECCHI, 2016, p. 3).

A falta de políticas públicas direcionadas para a educação ${ }^{7}$, o saneamento básico ${ }^{8}$, a igualdade de gênero ${ }^{9}$ e a saúde ${ }^{10}$ acarreta uma série de problemas que não têm sido tratados

\footnotetext{
${ }^{5}$ Conforme Elida Séguin (2004): “[...] o direito da população a um saneamento básico, água potável, serviço de limpeza urbana, drenagem das vias de circulação, energia elétrica, gás canalizado, abastecimento de alimentos e bens, iluminação pública, saúde pública, educação e cultura". Vide também o artigo 196 da Constituição Federal. ${ }^{6}$ Art. 196, da Constituição Federal - A saúde é direito de todos e dever do Estado, garantido mediante políticas sociais e econômicas que visem à redução do risco de doença e de outros agravos e o acesso universal igualitário às ações e serviços para sua promoção, proteção e recuperação.

${ }^{7}$ Objeto 4 da ODS. Educação de Qualidade - Assegurar a educação inclusiva e equitativa de qualidade, e promover oportunidades de aprendizagem ao longo da vida para todos.

${ }^{8}$ Objetivo 6 da ODS. Água potável e saneamento - Assegurar a disponibilidade e a gestão sustentável da água e saneamento para todos.

${ }^{9}$ Objetivo 5 da ODS. Igualdade de gênero. Alcançar a igualdade de gênero e empoderar todas as mulheres e meninas.

O desenvolvimento sustentável não será alcançado se as barreiras tangíveis e intangíveis que impedem o pleno desenvolvimento e exercício das capacidade de metade da população não forem atingidos.

${ }^{10}$ Vide referência 3.
} 
corretamente na sociedade brasileira. Além disso, verifica-se que as pessoas que não têm acesso a esse quarteto de necessidades básicas, são aquelas mesmas desprovidas de poder aquisitivo para compra de medicamentos necessários ao restabelecimento de sua saúde, devendo o poder público subsidiá-los ou fornecê-los a esses desatendidos.

O programa de distribuição gratuita de medicamentos, com parceria entre municípios, estados e governo federal por meio do Sistema Único de Saúde (SUS), é um exemplo salutar de política pública direcionada à área de saúde que deve ser expandida, não ficando circunscrito a apenas determinados medicamentos (MOURA, 2019) ${ }^{11}$.

Como demonstração de política pública adequada à saúde pública, vale destacar, no âmbito internacional, a ação da Organização Mundial de Saúde (OMS ou WHO em inglês), órgão da ONU, que, em sua 66 ${ }^{a}$ Assembleia Mundial da Saúde, ocorrida em Genebra de 20 a 28 de maio de 2013, aprovou o Plano de Ação Global da OMS para a Prevenção e o Controle de Doenças Não Transmissíveis 2013-2020. Entre outros assuntos tratados durante essa importante reunião, criou-se a Meta Voluntária $\mathrm{n}^{\circ}$ 9, estabelecendo a disponibilidade na ordem dos $80 \%$ de tecnologias de base e medicamentos essenciais a preços acessíveis, genéricos inclusive, necessários para tratar as principais doenças não transmissíveis (DNT), seja em unidades de saúde públicas ou privadas (Resolução WHA 66.10) (WHO, 2015) ${ }^{12}$.

Para que se tenha uma ideia do que ocorre na realidade brasileira, inclusive comparável com essas disposições internacionais, aborda-se adiante o Sistema de Saúde que vem sendo aplicado no País.

\section{UMA VISÃO DO SISTEMA DE SAÚDE BRASILEIRO}

O Sistema de Saúde no Brasil, antes da reforma ocorrida em 1990, estava estruturado em seis setores com autonomia de recursos, instalações e clientelas próprias: a) seguro social; b) Ministério da Saúde; c) funcionários públicos; d) militares; e) estados; f) municípios. Com o advento da Constituição Federal de 1988, o seguro social de saúde foi fechado e todo seu pessoal, instalações, recursos e usuários foram direcionados e unificados com os do Ministério da Saúde, além de coordenados no SUS com os dos estados e municípios (LAGO, 2007).

\footnotetext{
${ }^{11}$ Conforme Thaís Moura (2019): “Os medicamentos fornecidos pelo SUS são para o tratamento de câncer, diabetes e hipertensão. Em 16 de julho de 2019 houve a suspensão gratuita de 19 medicamentos para o tratamento de câncer, diabetes e transplantes, dificultando a vida daquelas pessoas com menor poder aquisitivo no tratamento de suas doenças ".

12 O Plano de Ação Global para a Prevenção e o Controle das DNT proporciona uma mudança de paradigma, submetendo um roteiro e uma lista de opções políticas aos Estados-Membros, à OMS, às demais organizações do sistema das Nações Unidas e organizações intergovernamentais, às ONGs e ao setor privado que, ao serem implementadas coletivamente entre 2013 e 2020, ajudarão a alcançar nove metas voluntárias globais, incluindo a da redução relativa de $25 \%$ na mortalidade prematura devida às DNT até 2025. Essas intervenções encontram-se definidas no Apêndice 3 do Plano de Ação Global para a Prevenção e o Controle das DNT 2013-2020.
} 
O Sistema de Saúde em vigor divide-se em dois setores: a) o Sistema Único de Saúde (SUS), público e gratuito, para oferecer o piso básico de atendimento para toda a população, mediante o abastecimento e o financiamento, dividindo-se em três níveis: federal, estadual e municipal ${ }^{13}$. É o setor de utilização principal pelas camadas mais pobres e de baixa renda, além de atender parte da classe média; b) setor privado, possuidor de caráter voluntário e complementar, regulamentado e controlado pelo governo federal. Terceiriza serviços com unidades do SUS, sendo utilizado por população de média e alta renda que possui seguros adicionais de saúde.

A reforma implementada significou grande progresso, mas ainda persiste o alto grau de segmentação do sistema, persistindo baixa integração, em função de subsistir a heterogeneidade de três tipos: 1) por possuir fornecedor público e privado de crescente importância; 2) por haver três níveis geográficos - federal, estadual e municipal -, cada um com funções próprias de direção, financiamento e fornecimento; 3) pela exclusão das Forças Armadas e algumas polícias estaduais, que mantiveram seus próprios programas, assim como os funcionários públicos federais que foram subsidiados apenas parcialmente (LAGO, 2007).

A Constituição Federal estabelece a participação social no SUS, sendo que a Lei ${ }^{\circ}$ 8.080, de 19 de setembro de 1990 , em seus artigos $5^{\circ}$ e $6^{\circ}$, definem os objetivos e seus campos de atuação (BRASIL, 2020b), inserindo-os no organograma do Ministério da Saúde. Assim, as políticas e os programas nacionais de saúde a serem elaborados envolvem os três níveis/esferas, ficando o nível federal encarregado de aportar a maior parte do financiamento público. Como no artigo $3^{\circ}$ deste mesmo diploma, os níveis de saúde expressam a organização social e econômica do País, tendo a saúde como determinante e condicionante (BRASIL, 2020b).

O SUS mantém o Conselho Nacional com participantes das três esferas e, quando é percebida alguma insuficiência regional ou local, se promovem ações para regularizá-las, supervisionadas e analisadas pelo Sistema. Observa-se que a regulação federal abrange também o setor privado, que atua no controle da qualidade dos serviços prestados, nos preços dos planos e seguros de saúde, e em mecanismos para recuperar custos de serviços utilizados no SUS (BRASIL, 2020a).

Na esfera estadual, as secretarias de Saúde realizam também funções reguladoras dentro das próprias áreas de atuação: de financiamento, parte por transferências federais e parte por suas próprias; de fornecimento, assim como de coordenar as ações de maior complexidade. No âmbito municipal ${ }^{14}$, as secretarias de Saúde dos municípios recebem recursos federais e

\footnotetext{
${ }^{13}$ Vide artigo, 23, II, da Constituição Federal.

14 Conforme Carmelo Mesa Lago (2007): “Os municípios possuem autonomia para solicitar seus serviços e avançam em direção a modelos assistenciais ou de polos municipais. Eles atendem a própria população e a de municípios vizinhos, ampliando assim o acesso. Contudo, as regulamentações federais estritas limitam a criatividade dos municípios para se adaptar às necessidades de saúde locais. A Constituição Federal estabelece a participação social no SUS que possibilita instrumento importante para garantir a execução de direitos e o controle de qualidade dos serviços".
} 
estaduais de acordo com as responsabilidades assumidas em sua área de atuação, mais precisamente em seu pacote básico e o Programa de Saúde da Família (LAGO, 2007).

O setor privado demanda a maior parte do gasto de saúde, funcionando independente do SUS, desprovido de vínculos organizacionais, institucionais e financeiros, exceto no que tange à regulação e supervisão federal. O setor é composto por empresas de medicina de grupo (principalmente pré-pagas); cooperativas médicas que restringem o uso a uma lista de fornecedores; grandes empresas com planos para seus funcionários; seguros médicos de reembolso; entidades filantrópicas; gastos à custa do próprio cidadão (LAGO, 2007) ${ }^{15}$.

Em 2008, 25,9\% da população brasileira dispunham de plano de saúde. Entre estas, $77,5 \%$ estavam vinculadas a planos de empresas privadas e $22,5 \%$ a planos de assistência ao servidor público. Além disso, do total de pessoas cobertas por plano de saúde, 47,8\% eram titulares do plano de saúde único ou principal que possuíam. O levantamento suplementar de saúde da Pesquisa Nacional por Amostra de Domicílios (PNAD) estimou em 139,9 milhões o total de pessoas que normalmente procuravam o mesmo serviço de saúde quando precisavam de atendimento, o que correspondia a $73,6 \%$ da população (IBGE, 2008) ${ }^{16}$.

Pesquisa realizada pelo Serviço de Proteção ao Crédito (SPC Brasil) e pela Confederação Nacional de Dirigentes Lojistas (CNDL) mostra que 69,7\% dos brasileiros não possuem plano de saúde particular, seja individual ou empresarial. Segundo este levantamento esse percentual é ainda maior entre as pessoas das classes C, D e E, atingindo 77\%. Destaca que $44,8 \%$ dos entrevistados sem plano de saúde disseram utilizar o SUS, principalmente os entrevistados das classes C, D e E $(51,4 \%)$, quando precisam de atendimento. O restante afirmou que arca com dinheiro do próprio bolso para pagar pelos serviços necessários (BOCCHINI, 2018).

Os dados mostram que o plano de saúde privada é considerado uma prioridade para grande parte de seus usuários. É serviço de primeira necessidade, quando correlacionado aos cuidados de um bem maior, que é a vida.

\subsection{Setor farmacêutico}

\footnotetext{
${ }^{15}$ Conforme Carmelo Mesa Lago(2007): "Em 1999, 43\% das instalações e 70\% das camas eram privadas, sendo que $58 \%$ dessas camas eram contratadas pelo SUS, além de que a imensa maioria dos equipamentos de alta tecnologia era privada".

${ }^{16}$ Conforme IBGE (2008): “O posto ou centro de saúde foi o local mais declarado como normalmente procurado $(56,8 \%)$, seguido pelos consultórios particulares $(19,2 \%)$ e pelo ambulatório de hospital (12,2\%). As demais categorias - farmácia, ambulatório de clínica ou de empresa, pronto-socorro e agente comunitário entre outros contabilizaram $11,8 \%$ dos locais procurados. O posto de saúde foi normalmente procurado principalmente pelas pessoas pertencentes às classes de rendimento mensal domiciliar per capita mais baixo. Para aqueles que viviam em domicílios com rendimento per capita de até $1 / 4$ do salário mínimo, 77,2\% procuravam regularmente este local para atendimento. Conforme aumentava o rendimento, a proporção de pessoas que procuravam este local se reduzia, atingindo apenas $4,8 \%$ entre aqueles com rendimento mensal domiciliar per capita de mais de cinco salários mínimos “.
} 
A Central Única de Medicamentos $(\mathrm{CEME})^{17}$ foi desativada em 1997, ensejando o processo de discussão com todos os setores nacionais interessados na definição das responsabilidades pela gestão e pelo financiamento da assistência farmacêutica nas três esferas do SUS. Nesse processo foram identificados e analisados os principais problemas do setor farmacêutico nacional, culminando com a publicação da Portaria $\mathrm{n}^{\circ} 3.916$, de 30 de outubro de 1998, que aprovou a Política Nacional de Medicamento (PNM), integrada à Política Nacional de Saúde (PNS) (OLIVEIRA; LABRA; BERMUDEZ, 2006).

A PNM tem os seguintes objetivos: assegurar os compromissos de governo e outras instâncias; garantir o acesso a medicamentos essenciais (OPS, 2005; WHO, 2015) ${ }^{18}$, principalmente para o atendimento de agravos prioritários de saúde da população; garantir a qualidade, eficácia e segurança dos medicamentos; promover o uso racional dos medicamentos.

A PNM é fundamental na descentralização da gestão, na promoção do uso racional dos medicamentos e na otimização e eficácia do gerenciamento da assistência farmacêutica. No cumprimento de sua missão apresenta oito diretrizes e prioridades: adoção da RENAME e da regulamentação sanitária de medicamentos; reorientação da assistência farmacêutica; promoção do uso racional de medicamentos (URM); desenvolvimento científico e tecnológico; promoção da produção de medicamentos; garantia da segurança, eficácia e qualidade dos medicamentos; desenvolvimento e capacitação de recursos humanos (OPS, 2005) ${ }^{19}$.

Na tentativa de implementação da PNM foram empreendidos esforços, lastreados nas metodologias propostas pela Organização Mundial da Saúde (OMS), que se desenvolveram entre 1998 a 2003 (OPS, 2005) ${ }^{20}$.

17 Conforme Oliveira; Labra; Bermudez (2006): "Iniciativas importantes da CEME foram o lançamento do Programa de Farmácia Básica (1987), que constava de uma seleção de aproximadamente 40 itens de medicamentos integrantes da Relação Nacional de Medicamentos Essenciais (RENAME), destinados ao uso ambulatorial (atenção primária), e o estabelecimento da Comissão Multidisciplinar de Revisão da RENAME (Portaria CEME n 45, de 14 de novembro de 1996). Em 1997, o governo federal desativou a CEME, através da Medida Provisória $n^{\circ} 1.576$, do Decreto $n^{\circ} 2.283$ e da Portaria GM n ${ }^{\circ} 1.085$. Suas competências, planos e programas foram sendo assumidos, aos poucos, por várias instâncias do Ministério da Saúde e também pelos estados e municípios".

${ }^{18}$ Conforme OMS (2015): "A OMS considera medicamentos essenciais aqueles que servem para satisfazer as necessidades de atenção à saúde da maioria da população. São selecionados de acordo com sua relevância na saúde pública, evidência sobre a eficácia e a segurança e os estudos comparativos de custo efetividade. Devem estar disponíveis a todo o momento, nas quantidades adequadas, nas formas farmacêuticas requeridas e a preços que os indivíduos e a comunidade possam pagar. No Brasil a relação de medicamentos essenciais é atribuição da RENAME".

19 As prioridades da PNM são: revisão permanente da RENAME; reorientação da assistência farmacêutica; promoção do uso racional de medicamentos; organização das atividades de vigilância sanitária de medicamentos. O planejamento orçamentário, que viabiliza o cumprimento das diretrizes, dos objetivos e das metas, foi realizado por meio do Plano Plurianual atualizado em 2003, definindo as atividades, as responsabilidades, o orçamento e os seus prazos de aplicação.

${ }^{20}$ Em 1998 - Avaliação do Programa Farmácia Básica: programa criado com o intuito de contornar possível crise de desabastecimento de medicamentos no SUS no período entre a extinção da CEME e a discussão e publicação da PNM, que propiciaria o redesenho do sistema de abastecimento; 1999 - avaliação do incentivo a assistência farmacêutica básica: modelo de financiamento do abastecimento de medicamentos, definido a partir da PNM e implicando a participação das três esferas de governo para os medicamentos utilizados na atenção básica de saúde, com a descentralização dos procedimentos de programa e aquisição para os estados e municípios; 2001 - estudo 
O órgão responsável pela regulamentação da área de medicamentos é a Vigilância Sanitária, criada pela Lei $\mathrm{n}^{\circ}$ 6.360, de 23 de setembro de 1976, à qual ficam sujeitos os medicamentos, as drogas, os insumos farmacêuticos e correlatos, cosméticos, saneantes e outros produtos $^{21}$. Por sua vez, a Lei $\mathrm{n}^{\circ}$ 9.782, de 26 de janeiro de 1999, criou o Sistema Nacional de Vigilância Sanitária (SNVS) e a Anvisa ${ }^{22}$, cujo regulamento foi aprovado pelo Decreto $\mathrm{n}^{\text {o }}$ 3029, de 16 de abril de 1999.

Nesse período o Brasil já possuía cerca de 400 empresas farmacêuticas. Dessas, 20 multinacionais dominam cerca de $80 \%$ do mercado, enquanto as 380 empresas de capital nacional são responsáveis por, aproximadamente, $20 \%$ do faturamento total. Cabe salientar que o parque industrial brasileiro de medicamentos é bastante desenvolvido com relação à capacidade de fabricação de produtos finais. Concomitantemente a isso, se constata o desenvolvimento na produção, evidenciando forte dependência da importação de farmacoquímicos principalmente vindos da Índia.

\subsection{A atuação das empresas farmacêuticas}

Os medicamentos se tornaram imprescindíveis para a sociedade brasileira, estando sob o controle de poucas empresas da área farmacêutica, que atuam de forma globalizada. Tal processo iniciou-se na década de 1980, com a fusão dos maiores laboratórios existentes no mercado mundial, com o objetivo de aumentar a rentabilidade dos negócios e obter maiores aportes de investimentos, ocasionando que esses conglomerados conquistem o domínio de 40,4\% do mercado mundial. Nos anos 1990, as fusões prosseguiram e atualmente 100 companhias de grande porte são responsáveis por cerca de $90 \%$ dos produtos farmacêuticos para o consumo humano (OLIVEIRA; LABRA; BERMUDEZ, 2006) ${ }^{23}$.

No Brasil existem 21 laboratórios oficiais que produzem juntos cerca de $30 \%$ dos medicamentos utilizados no SUS. Além disso, com os acordos, o Ministério da Saúde garante a produção dos medicamentos antes comprados de empresas privadas, muitas delas estrangeiras, estimando uma grande economia nos gastos com a compra de medicamentos

multicêntrico: Strategies for enhancing access to medicines (SEAM-MG), estudo financiado pela Fundação Bill e Melinda Gates; 2001 - organização da assistência farmacêutica nos municípios brasileiros; 2003 - Diagnóstico da Farmácia Hospitalar no Brasil: com a finalidade de conhecer os aspectos da estrutura e do processo das farmácias hospitalares no País, criando as bases para o monitoramento desse segmento nos âmbitos público e privado.

21 Até 1999, a regulação sanitária de medicamentos era de responsabilidade da extinta Secretaria Nacional de Vigilância Sanitária do Ministério da Saúde.

22 A Anvisa é uma autarquia sob regime especial vinculada ao Ministério da Saúde ou seja, uma agência reguladora, caracterizada pela independência administrativa, estabilidade de seus dirigentes durante o período de mandato e autonomia financeira, possuindo autoridade na sua execução de forma complementar e integrada com as vigilâncias sanitárias estaduais e municipais.

23 Conforme Oliveira;Labra;Bermudez (2006): “Cerca de 75\% dessa produção é consumida, principalmente, nos Estados Unidos, Japão, Alemanha, França, Itália e Reino Unido. Nesses países, a proporção maior dos gastos com pesquisa e desenvolvimento (P\&D) tem sido direcionada ao atendimento de demandas de suas populações, por exemplo, doenças crônico-degenerativas ou problemas como calvície, enxaqueca, depressão, substâncias que, eventualmente, atuariam no adiamento do envelhecimento ou no controle da obesidade ". 
(BRASIL, 2020g) ${ }^{24}$. No entanto, tais laboratórios ainda operam de forma quase ociosa, pois têm capacidade de produzir, aproximadamente, 11 bilhões de unidades farmacêuticas/ano, com 195 apresentações farmacêuticas, abrangendo mais de 107 princípios ativos. Para se chegar à produção plena, é necessário existir uma política industrial, científica, tecnológica e de saúde pública que oriente seu funcionamento.

Em 2017, o Brasil subiu duas posições no ranking global, tornando-se o sexto maior mercado farmacêutico do mundo, atrás apenas dos Estados Unidos, da China, do Japão, da Alemanha e da França, segundo a IQVIA ${ }^{25}$ (GUIADAFARMACIA, 2018) ${ }^{26}$. Diante desse panorama, é o caso de se verificarem as obrigações do Estado, com relação aos Objetivos de Desenvolvimento Sustentável (ODS).

\section{O ESTADO E SUAS OBRIGAÇÕES}

Em 2015, a ONU propôs aos países membros uma nova agenda de desenvolvimento sustentável para os próximos 15 anos, a Agenda 2030, composta pelos 17 Objetivos de Desenvolvimento Sustentável (ODS), tendo o Brasil aquiescido no cumprimento da proposta. Os princípios da Agenda 2030 e dos ODS se resumem no seguinte: universalidade - são relevantes para todas as pessoas; integração - equilibra as dimensões ambiental, social e econômica; não deixar ninguém para trás, pois os ODS têm a intenção de beneficiar todas as pessoas em todos os lugares. (PACTO GLOBAL, 2020).

Apesar do inegável progresso mundial, especialmente no avanço tecnológico, as doenças crônicas e as resultantes de desastres continuam sendo os principais fatores que causam a pobreza e a privação de insumos básicos para os mais vulneráveis. Atualmente, $63 \%$ de todas as mortes no mundo provêm de DNT, principalmente cardiovasculares, respiratórias, câncer e

${ }^{24}$ Os Laboratórios Oficiais são: Instituto de Tecnologia em Imunobiológicos (Bio-Manguinhos), no Rio de Janeiro-RJ; Instituto de Tecnologias em Fármacos (Far-Manguinhos), no Rio de Janeiro-RJ; Fundação Ezequiel Dias (FUNED), em Belo Horizonte-MG; Fundação para o Remédio Popular (FURP), em Guarulhos-SP; Indústria Química do Estado de Goiás (IQUEGO), em Goiânia-GO; Instituto Vital Brazil (IVB), em Niterói-RJ; Laboratório Farmacêutico do Estado de Pernambuco S.A. (LAFEPE), em Recife-PE; Laboratório Farmacêutico do Rio Grande do Sul (LAFERGS), em Porto Alegre-RS; Laboratório Químico Farmacêutico da Aeronáutica (LAQFA), no Rio de Janeiro-RJ; Laboratório de Ensino, Pesquisa e Extensão em Medicamentos e Cosméticos/ Unidade de Produção de Medicamentos da Fundação Universidade de Maringá (FUEM/LEPEMC/UPM), em Maringá- PR; Laboratório Industrial Farmacêutico de Alagoas S.A. (LIFAL), em Maceió-AL; Laboratório Industrial Farmacêutico do Estado da Paraíba (LIFESA), em João Pessoa-PB; Laboratório Farmacêutico da Marinha (LFM), no Rio de Janeiro-RJ; Laboratório de Produção de Medicamentos (LPM), em Londrina-PR; Laboratório Químico Farmacêutico do Exército (LQFEX), no Rio de Janeiro-RJ; Laboratório de Tecnologia Farmacêutica (LTF), em João Pessoa-PB; Núcleo de Pesquisa em Alimentos e Medicamentos (NUPLAM), em Natal-RN; Fundação Universidade do Amazonas (FUAM), em Amazonas-MA; Núcleo de Tecnologia Farmacêutica (NTF), em Teresina-PI; Empresa Brasileira de Hemoderivados e Biotecnologia (Hemobrás), em Brasília-DF.

${ }^{25}$ (NYSE:Q) é uma empresa líder global no fornecimento de informação, soluções tecnológicas inovadoras e serviços de investigação clínica focada no uso de dados e ciência para ajudar clientes da área da saúde a encontrar melhores soluções para os seus pacientes.

${ }^{26}$ Conforme Guiadafarmacia (2018): “O investimento em P\&D para a produção de medicamentos em nosso país é irrelevante, em torno de $0,53 \%$ de seu faturamento na referida atividade. Enquanto isso, a média de todas as empresas nos demais setores foi de 1,33\%. Apesar da excelente margem de lucro, não tem havido investimento tecnológico em empresas, estrangeiras ou nacionais, públicas ou privadas, instaladas no país “. 
diabetes. Estima-se que as perdas econômicas para os países de renda média e baixa provenientes dessas doenças ultrapassarão US\$ 7 trilhões até 2025.

André-Pierre Contandriopoulos, falando sobre o desafio do acesso a medicamentos em sistemas de saúde, esclareceu que os países têm problemas semelhantes na dificuldade de fornecer diversos serviços, entre eles, o acesso a medicamentos, pela existência de listas de espera inaceitáveis e também pela enorme disparidade existente entre as camadas sociais, no que diz respeito a contar com esses serviços em seu benefício (CONTANDRIOPOULOS, 2010).

Se o direito de acesso a medicamento pela população mais vulnerável for obstado, inibindo o tratamento adequado de sua enfermidade, ela poderia se socorrer ao Poder Judiciário? Sim, pois é livre o acesso. Contudo, se o Estado alegar e provar o comprometimento orçamentário como razão para a não disponibilização de medicamento, utilizando o princípio da reserva do possível, o pleito poderá ser indeferido. Esse princípio significa "o limite ao poder do Estado de concretizar efetivamente direitos fundamentais a essa prestação" (SARLET; FIGUEIREDO, 2010) ${ }^{27}$. Entretanto, tal recorrência vai depender do caso concreto a ser analisado pelo Judiciário ${ }^{28}$.

Existem diversos motivos que impedem o Estado de cumprir com suas obrigações, no que tange ao atendimento às necessidades da saúde da população: falta de recursos e de pessoal, em especial nos hospitais; espera relativamente longa para atendimentos; desvalorização da medicina de primeira linha (atenção primária); tensões frequentes entre a assistência pública e os seguros privados de saúde; repetidos escândalos na prestação de saúde às pessoas menos favorecidas e aos idosos; grandes distâncias geográficas que dificultam o acesso aos serviços; a incapacidade de controlar a alta de preços dos medicamentos e de garantir seu acesso com uso racional (CONTANDRIOPOULOS, 2010). O mesmo autor faz a seguinte afirmativa:

[...] se o aumento de custos estivesse associado a um ganho importante para saúde das pessoas, certamente poderia ser visto como benefício, porém ao comparar-se esse aumento com a esperança de vida ao nascer, que é um indicador de saúde, onstata-se que não há relação entre a elevação dos custos e a melhoria na saúde da população ${ }^{29}$ (CONTANDRIOPOULOS, 2010, p. 18).

\footnotetext{
${ }^{27}$ Vide também: JACOB, Cesar Augusto Alckmin. A “reserva do possível”: obrigação de previsão orçamentária e de aplicação da verba. In: GRINOVER, Ada Pellegrini; WATANABE, Kazuo (Org.). O controle jurisdicional das políticas públicas. 2. ed. Rio de Janeiro: Forense, 2013, p. 237-284.

${ }^{28}$ Vide (Superior Tribunal de Justiça - Resp 1762423 CE 2018/0220698-0, Relator: Ministro Og Fernandes, Data de Publicação: DJ 24/09/2018).

${ }^{29}$ Conforme Contandriopoulos (2010, p. 18): "Para exemplificar, com a base de dados de 2004, o Japão com gastos aproximados de $8,25 \%$ do Produto Interno Bruto (PIB) com saúde apresenta uma esperança de vida ao nascer de 82,2 anos, enquanto o Reino Unido, com o mesmo gasto, apresenta para esse indicador a idade de cerca de 78,7 anos. Nos EUA, com um gasto em saúde de aproximadamente 15,4\% do PIB, a esperança de vida ao nascer corresponde a 77,6 anos, muito próxima da Dinamarca que gastou 8,9\% do PIB".
} 
Em resposta às referidas questões, Contandriopoulos esclarece que há dois grupos de países: aqueles que dispõem de sistema público financiado, de forma importante, pelo Estado ou por quotização social; os Estados Unidos e a Suíça, nos quais as despesas privadas são significativas. Quando observados o percentual de despesa privada e o aumento dos custos pode-se perceber que existe relação linear entre eles: quanto mais os países têm sistema público, mais fácil torna-se o controle de custos; enquanto nos que tem sistema misto público-privado, mais difícil é esse controle (CONTANDRIOPOULOS, 2010). O mesmo autor acredita que

[...] para se ter um sistema realmente à altura das expectativas da população, deverse-ia aumentar o financiamento público; integrar os serviços e melhorar sua qualidade; organizar a atenção primária; repensar a governança e a imputabilidade; desenvolver prontuários médicos únicos e utilizáveis por todos os profissionais; e garantir o acesso universal e equânime aos medicamentos. Porém, apesar de essas recomendações serem convergentes, é preciso reconhecer que os resultados estão longe das expectativas. Fala-se sobre o que deve ser feito, mas frequentemente não se faz o que deveria ser feito. Tem-se, então, a impressão de que as reformas propostas não têm a capacidade de modificar a trajetória do sistema de saúde e de organizar as transformações requeridas para permitir o encontro da tríplice exigência de ser equidade, liberdade e eficiência (CONTANDRIOPOULOS, 2010, p. 20).

Observe-se que o acesso equânime aos medicamentos é igualmente difícil de se garantir. Trata-se de componente essencial para a preservação da saúde e não se pode criar impasse nessa área negando o acesso, em especial considerando que a saúde é um direito e o Estado é seu provedor, devendo assegurar a cada pessoa, por políticas públicas próprias, o tratamento prescrito. Por outro lado, os medicamentos muitas vezes indispensáveis ao tratamento são cada vez mais onerosos, se bem que imprescindíveis. Conforme reiterado em diversas oportunidades, o fato de o Estado não garantir o acesso a tratamento adequado para o cidadão agride o direito à saúde assegurado na Constituição Federal.

Constata-se que a despesa per capita com medicamentos em diferentes países é muito variável, sendo também a responsabilidade pública em relação a eles muito variável. Aviva o autor que, quanto à regulação dos medicamentos, coexistem quatro lógicas: 1) lógica do mercado (importância do lucro e responsabilidade social), 2) lógica profissional (independência profissional); 3) lógica democrática (o papel do Estado no atendimento dos seguintes direitos: o direito à saúde e ao acesso a medicamentos com equidade; o direito à propriedade intelectual das farmacêuticas, que constituem parte importante do produto interno bruto - PIB); 4) lógica tecnocrática (é preciso levar em conta a complexidade do tema e encontrar o ponto de equilíbrio entre a necessidade de estabelecer condutas clínicas e terapêuticas e a manutenção da liberdade profissional, conhecida como governança clínica) (CONTANDRIOPOULOS, 2010) ${ }^{30}$.

\footnotetext{
${ }^{30}$ Conforme Contandriopoulos (2010): "Na maioria dos países (Dinamarca, Suécia, Finlândia, Noruega, Austrália, Suíça, Alemanha e França) as despesas públicas com esse insumo são superiores às despesas privadas. Existem duas exceções: Canadá e Estados Unidos. Quando se comparam as despesas do setor farmacêutico com as despesas totais dos sistemas de saúde, constata-se que aqueles aumentam mais rapidamente que estes, em todos os lugares. Entretanto, há exceções, na Suécia se consegue controlar as despesas com medicamentos”.
} 
A menção às quatro lógicas sobre as quais discorre o autor conduz a duas considerações: a) nenhuma delas, sozinha, mostra-se suficiente para assegurar a regulação do sistema, independentemente de como ele seja; b) para que uma decisão seja tomada e seja útil, é preciso basear-se em uma dessas lógicas. Daí, Contandriopoulos propõe as seguintes questões: Que lógica prevalece sobre a outra e quando isto ocorreria? Esse impasse pode ser solucionado? Sua resposta é afirmativa, mas implica a ocorrência de um ou mais dos seguintes eventos: a) se a regulação democrática, conduzida pelo mundo político, pudesse assegurar a independência da pesquisa; que pudesse garantir, de maneira rígida e sem nenhuma exceção, a independência da expertise na avaliação da eficácia e da segurança dos novos produtos; b) revisão da legislação com respeito à duração das patentes; c) a colocação em prática da prestação de informações completas sobre os medicamentos, obrigando a indústria a rever todos os resultados de suas pesquisas, incluindo aquelas mantidas em segredo; d) o financiamento suficiente à formação inicial e contínua de profissionais; e se o controle dos preços de medicamentos fosse feito pelo governo e não pelas indústrias; e) o controle da publicidade, principalmente aquela voltada para impactar diretamente a população; f) a continuação da reforma dos sistemas de saúde, principalmente aqueles que garantam a universalidade do acesso aos medicamentes e que constituem elemento importante de programas públicos de seguro-saúde (CONTANDRIOPOULOS, 2010, p. 21-25).

Cabe, em seguida, abordar a interface entre os princípios que possam garantir o acesso ampliado aos medicamentos e os interesses das indústrias farmacêuticas do país e do exterior.

\section{ACESSO A MEDICAMENTOS VERSUS AS INDÚSTRIAS FARMACÊUTICAS}

O acesso a medicamentos, segundo a OMS, está relacionado com a seleção racional, preços acessíveis, sistemas de financiamento sustentáveis e sistemas de abastecimento de medicamentos confiáveis.

Thomas Pogge assevera que cerca de 3,4 bilhões de pessoas detêm menos de $2 \%$ da renda global, em comparação com os $6 \%$ dessa renda recebida por $1 \%$ das famílias americanas mais ricas, que constituem três milhões de pessoas. E a discrepância aumenta rapidamente não somente em termos mundiais, mas também no âmbito doméstico da maioria dos países. Em época recente, a desigualdade de renda tem diminuído de forma clara somente em quatro países e o Brasil é um deles, mas ainda está entre as sociedades mais desiguais, com a metade mais pobre ganhando apenas $14 \%$ de toda a renda familiar, em comparação com os $45 \%$ dos $10 \%$ mais ricos (POGGE, 2008). 
As mencionadas cifras demonstram que os pobres estão alijados do acesso a medicamentos $^{31}$, pois, conforme assevera o Acordo TRIPS $^{32}$, o preço alto para medicamentos avançados os deixa fora do alcance dos pacientes pobres ${ }^{33}$ e estimula a negligência de doenças concentradas nessas populações ${ }^{34}$.

As pessoas mais pobres estão expostas a doenças contagiosas, entre outras agressivas enfermidades, e carecem de meios para protegê-las e a seus familiares, pois não têm acesso a saneamento básico adequado, não contam com boas condições de higiene e são desprovidos de prestígio que lhes assegurem a destinação de políticas públicas em seu benefício. Carecem, também, de reservas financeiras e de acesso às fontes públicas de conhecimento e tratamento médico adequado para concorrer no espaço social de forma igualitária com os demais. Permanecem, assim, em situação crônica de vulnerabilidade, sem perspectivas de evolução social.

Na visão de Pogge (2008, p. 124) tal situação pode ser alterada desde que se efetivem progressos contra a carga global das doenças (CGD), pois essas doenças afastam, temporariamente ou permanentemente, pessoas do mercado de trabalho. Caso seja empreendida a reforma do financiamento à prestação de tratamentos médicos, tal situação poderá ser melhorada para a clientela em questão.

É salutar esclarecer que existem três categorias de medicamentos: a) os curativos, que removem a doença do corpo do paciente; b) os que aliviam os sintomas e melhoram o bemestar e o funcionamento do corpo, sem remover a doença; c) os preventivos, que reduzem a probabilidade de contrair a doença. Os medicamentos que aliviam os sintomas são os mais lucrativos, pois os pacientes mais desejáveis são aqueles que não são curados e não morrem, uma vez que continuam adquirindo o medicamento regularmente, favorecendo a indústria farmacêutica detentora da patente ${ }^{35}$.

\footnotetext{
${ }^{31}$ Segundo a OMS, o acesso a medicamentos está relacionado com a seleção racional, preços acessíveis, sistemas de financiamento sustentáveis e sistemas de abastecimento de medicamentos confiáveis.

32 O Acordo TRIPS (em inglês: Agreement on Trade-Related Aspects of Intellectual Property Rights; em português: Acordo sobre Aspectos dos Direitos de Propriedade Intelectual Relacionados ao Comércio) é um tratado Internacional integrante do conjunto de acordos assinados em 1994, que encerrou a Rodada Uruguai e criou a Organização Mundial do Comércio (OMC).

${ }^{33}$ Conforme Thomas Pogge (2008): "Hoje em dia, cerca de 100 companhias farmacêuticas de grande porte são responsáveis por cerca de $90 \%$ dos produtos farmacêuticos para consumo humano.

Por sua vez, $75 \%$ dessa produção é consumida, principalmente, nos Estados Unidos, Japão, Alemanha, França, Itália e Reino Unido. Nesses países, a proporção maior dos gastos com pesquisa e desenvolvimento (P\&D) tem sido direcionada ao atendimento de demandas de suas populações, por exemplo, doenças crônico-degenerativas ou problemas como calvície, enxaqueca, depressão, substâncias que eventualmente atuariam no adiamento do envelhecimento ou no controle da obesidade".

${ }^{34}$ Essa negligência se concentra no fato de as grandes empresas farmacêuticas preferirem desenvolver produtos destinados a público possuidor de recursos para comprar seus produtos, como aqueles para queda de cabelo, remoção de acne etc., em vez de investir em pesquisa para doença de Chagas, tuberculose, doença do sono, entre outras.

${ }^{35}$ Os medicamentos que aliviam a dor colocam o pobre e o rico no mesmo pé de igualdade, pois não terão sua doença curada e ficarão à mercê do medicamento por longo período de sua vida.
} 
Argumenta o autor que o mundo reage de diversas formas contra a crise catastrófica da saúde que atinge as populações de menor renda: com as habituais declarações, informes, conferências, reuniões de cúpula e grupos de trabalho usuais, mas também com tentativas de financiar o fornecimento de medicamentos aos pobres por meio de iniciativas intergovernamentais, com a "3 em 5"36, mediante programas governamentais como o Plano de Emergência do Presidente dos EUA para Alívio da Aids (PEPFAR), por meio de parcerias público-privadas, como a Aliança Global para Vacinas e Imunização (GAVE) e o Fundo Global para Combater a Aids, Tuberculose e Malária (GFATM). Ocorrem, também, doações de remédios das companhias farmacêuticas, bem como esforços variados para promover o desenvolvimento de novos medicamentos para as moléstias dos pobres, como a Iniciativa de Medicamentos para Doenças Negligenciadas (DNDi), o Instituto para Uma Saúde Mundial (One World Health - IOWH), o Instituto Novartis para Doenças Tropicais e vários prêmios, bem como compromissos antecipados de compra $^{37}$ e compromissos antecipados de mercado (POGGE, 2008) ${ }^{38}$.

Constatou-se, no decorrer dos anos, que os programas mencionados aplicaram bilhões de dólares para neutralizar o custo imposto aos pobres do mundo pela globalização das patentes monopolizadas, cujas ações foram materializadas com a criação OMC, mas não atingiram de forma plena seu objetivo.

Torna-se intangível pensar que este objetivo seja alcançado, se for tratado pela ótica das empresas farmacêuticas, com base aos pontos apresentados por Pogge (2008, p. 129-131) a seguir: a)devido aos preços altos dos remédios - os preços praticados pelas empresas farmacêuticas estão diretamente ligados à proteção de sua patente e, enquanto ela estiver em vigor, os preços não vão diminuir, pois o lucro é o objetivo principal, senão único, do empresário; b) negligência em relação às doenças concentradas nas populações pobres, por mais disseminadas que sejam essas doenças - o público-alvo está em países pobres e o custobenefício para as empresas não é atrativo, motivo suficiente para serem deixadas de lado as pesquisas destinadas à cura dessas enfermidades; c) preferência pelo alivio de sintomas - a

\footnotetext{
${ }^{36}$ Anunciado em 2003, este programa conjunto WHO/UNAIDS destinava-se a fornecer, até 2005, tratamento antirretroviral a 3 milhões (do que era então estimado em 40,3 milhões) de pacientes de Aids nos países menos desenvolvidos. Na realidade, o número de pacientes que receberam esse tratamento aumentou somente em 0,9 milhão e chegou a 1,3 milhão no final de 2005.

${ }^{37}$ Conforme Thomas Pogge (2008): Um compromisso antecipado de compra (APC) é uma promessa de compra, a um preço preestabelecido e lucrativo, de um grande número determinado de doses de um medicamento novo que obedece a certas especificações.

Constata-se situação similar sendo aplicada no Brasil entre o Ministério da Saúde (MS) e algumas empresas farmacêuticas privadas, sob a denominação de Parcerias para o Desenvolvimento Produtivo (PDPs), sendo que estas empresas têm seu estoque adquirido pelo MS para utilização pelo Sistema Único de Saúde (SUS), pelo prazo de cinco anos.

${ }^{38}$ Conforme Thomas Pogge (2008): Um compromisso antecipado de mercado (AMC) é uma promessa de subsidiar a venda de grande número determinado de doses de um medicamento novo que obedece a certas especificações. O único AMC emitido até agora - financiado por Itália, Reino Unido, Canadá, Rússia, Noruega e a Fundação Gates - é para vacinas contra doença pneumocócica, causa importante de pneumonia e meningite entre as populações pobres. Novos relatórios sugerem que ele está projetado para servir, sobretudo aos interesses da indústria farmacêutica.
} 
empresas farmacêuticas querem lucrar e vão lucrar muito mais se não curarem as doenças, mas somente entregarem medicamentos que aliviem os sintomas e melhorem o bem-estar; d) desperdício - para implantar seu produto num Estado, a empresa precisa obter sua aprovação em órgão estatal próprio. Tal providência implica despesas, assim como o monitoramento dessas jurisdições, a fim de impedir possíveis violações de suas patentes; e) falsificação quando o preço de venda de determinado produto está muito acima de seu custo de fabricação (mark-up), isto incentiva a manufatura e venda ilegal desses medicamentos; f) marketing excessivo - se o mark-up for muito grande, as indústrias farmacêuticas julgam viável fazer esforços especiais para aumentar o volume de vendas influenciando o receituário dos médicos, assediando-os com promotores de venda; g) "problema de última milha" - a companhia farmacêutica que desenvolvesse esforço moralmente motivado para permitir aos pobres se beneficiarem de seu medicamento patenteado, correria o risco de prejudicar seriamente sua posição econômica. Quando arcar com o esforço para tornar o remédio disponível de forma adequada aos pacientes pobres, promovendo a ocorrência de doença da qual dependem seus lucros, vai também perder os clientes ricos, que vão encontrar maneira de comprar barato medicamentos destinados aos pobres; h) licenças compulsórias - promovidas por alguns governos, a fim de obter para suas populações acesso mais barato a medicamentos patenteados ${ }^{39}$.

Tal situação pode ser modificada, segundo o autor, por meio da implantação do Fundo de Impacto sobre a Saúde Global (Health Impact Fund), no sentido de promover, junto àqueles que detêm a patente dos medicamentos, a opção de oferecer os medicamentos a preço de custo, em troca de uma recompensa monetária anual baseada no impacto que tal iniciativa possa acarretar aos negócios.

\section{CONSIDERAÇÕES FINAIS}

A saúde atingiu o status de Direito Humano Fundamental há sete décadas na sociedade internacional, bem como em diversas constituições ao redor do mundo, mas para se tornar direito exercido na prática, implica outro patamar a ser alcançado. Tal situação prática pode ser constatada no caso dos medicamentos que, mesmo prevista no terceiro item dos Objetivos de Desenvolvimento Sustentável (ODS) a serem alcançados até 2030, sua execução tem sido severamente inibida pelas dificuldades que se apresentam a cada momento.

Existe necessidade premente de se institucionalizarem mecanismos no sentido de os grandes conglomerados farmacêuticos internacionais desenvolverem pesquisas para o tratamento de doenças com habitat no Terceiro Mundo. É crucial haver a mediação do Estado no fomento e na gestão em P\&D de medicamentos direcionados aos problemas de saúde das

\footnotetext{
39 Apesar de permitidas especificamente pelo acordo TRIPS e reafirmados pela Declaração de Doha (vide: <https://bioeticaediplomacia.org/wp-content/uploads/2013/10/Declaracao-sobre-o-Acordo-de-TRIPS.pdf>), as licenças compulsórias são energicamente condenadas pelos laboratórios. As administrações governamentais que ousam emiti-los costumam ser censuradas e penalizadas por essas empresas e pelos governos dos países ricos que defendem os interesses delas.
} 
áreas mencionadas. Entretanto, tal iniciativa implica haver acordo entre as farmacêuticas internacionais e os Estados, no qual não haja perdas consideráveis para nenhuma das partes: nem para as farmacêuticas, devido ao investimento aplicado na produção do medicamento; nem para o Estado, não sendo extorquido pelo preço abusivo que seja cobrado pelos medicamentos adquiridos.

O Estado brasileiro deve ter atuação mais contundente diante das indústrias farmacêuticas, com seu poder econômico e de lobby. Para isso, se faz necessário o investimento robusto em pesquisa e desenvolvimento nos laboratórios do governo; na aquisição de insumos; no estabelecimento de normas para a produção, registro, comercialização, distribuição e dispensação de medicamentos; no controle mais efetivo das farmacêuticas, em suas propagandas reproduzidas nas mídias divulgando medicamentos que aliviam os sintomas e melhoram o bem-estar e o funcionamento do corpo, mas não curam as doenças; em campanhas de uso racional de medicamentos e seu controle. Todas essas providências são indispensáveis a fim de atender as necessidades e as expectativas da população, atingindo especialmente a camada mais pobre, sem condições plenas de acesso aos medicamentos essenciais direcionados às suas doenças mais frequentes. Tal iniciativa vem ao encontro ao descrito na Política Nacional de Medicamento (PNM), integrada à Política Nacional de Saúde (PNS) e àqueles nominados por Contandriopoulos (2010) em sua proposta amplamente abordada.

Há consciência de que essas medidas sejam de difícil realização no momento atual, entretanto devem ser expostas e discutidas, para promover a mobilização e o esforço do Estado no sentido de assegurar o direito humano de os setores mais carentes da população terem acesso aos medicamentos, por iniciativa ou não do poder público, evitando se privar do indispensável para sua subsistência. No caso do Brasil, trata-se de situação com dependência direta em vários fatores, entre eles a dotação orçamentária vinculada a três instrumentos normativos - o Plano Plurianual, a Lei de Diretrizes Orçamentárias e a Lei Orçamentária Anual - formatados na Constituição Federal.

A proposta apresentada por Pogge (2008), extensivamente abordada neste trabalho, situa-se numa posição intermediária para a defesa do escopo de ambas as partes: as empresas farmacêuticas não lucram o desejado, mas obterão significativa compensação pelo desenvolvimento tecnológico custeado pelo Estado até a descoberta do remédio desejado; os pobres, sem recursos econômicos que lhes permitam a compra do remédio, serão atendidos em suas necessidades mais prementes. Diante da possibilidade de um acordo desse tipo, vale a pena especular: será que as farmacêuticas vão considerá-lo viável? A queda de braços entre o Estado e as farmacêuticas seja talvez o óbice mais evidente para inviabilizar a negociação. Resta ficar na indagação, pois, conforme se abordou neste artigo, os interesses mercantilistas se apresentam com maior relevância que a observância aos valores da dignidade da pessoa humana.

Entretanto, surge desponta a esperança de que tal acerto possa ser alcançado, desde que sejam concretizadas as propostas da ODS (objetivos 3,4,5 e 6). Ocasião em que todas as pessoas 
se conscientizarão sobre o conjunto de princípios e valores que têm a função de garantir a cada cidadão o respeito e observância de seus direitos pelo Estado onde reside.

\section{REFERÊNCIAS}

BARROSO, Luís Roberto. A dignidade da pessoa humana no direito constitucional contemporâneo: natureza jurídica, conteúdos mínimos e critérios de aplicação. Versão provisória para debate público. Mimeografado, dez. 2010.

BOCCHINI, Bruno. Pesquisa mostra que quase $70 \%$ dos brasileiros não têm plano de saúde. Agência Brasil. Disponível em: <https://agenciabrasil.ebc.com.br/ eral/noticia/201802/pesquisa-mostra-que-quase-70-dos-brasileiros-nao-tem-plano-de-saude-particular>.

Acesso em: 02 abr. 2020.

BRASIL. Lei $\mathrm{n}^{\circ}$ 6.360, de 23 de setembro de 1976. Diário Oficial da União, Brasília, DF, 24 set. 1976. Dispõe sobre a Vigilância Sanitária a que ficam sujeitos os Medicamentos, as Drogas, os Insumos Farmacêuticos e Correlatos, Cosméticos, Saneantes e Outros Produtos, e dá outras Providências. Disponível em: 〈http://www.planalto.gov.br/ccivil_03/leis/16360.htm>. Acesso em: 3 abr. 2020a.

BRASIL. Lei ${ }^{\circ}$ 8.080, de 19 de setembro 1990.Diário Oficial da União, Brasília, DF, 20 set.1990. Dispõe sobre as condições para promoção, proteção e recuperação da saúde, a organização e o funcionamento dos serviços correspondentes e dá outras providências. Disponível em: http://www.planalto.gov.br/ccivil_03/leis/18080.htm. Acesso em: 8 abr. 2020b.

BRASIL. Constituição da República Federativa do Brasil. Diário Oficial da União, Brasília, DF, 5 out. 1988. Disponível em: <http://www.planalto.gov.br/ ccivil_03/Constituicao/Constituicao.htm>. Acesso em: 6 abr. 2020c.

BRASIL. Lei $n^{\circ}$ 8.142, de 28 de dezembro de 1990. Diário Oficial da União, Brasília, DF, 31 dez. 1990. Dispõe sobre a participação da comunidade na gestão do Sistema Único de Saúde (SUS) e sobre as transferências intergovernamentais de recursos financeiros na área da saúde e dá outras providências. Disponível em: 〈http://www.planalto.gov.br/ccivil_03/leis/ L8142.htm>. Acesso em: 2 abr. $2020 \mathrm{~d}$.

BRASIL. Lei no 9.782, de 26 de janeiro de 1999. Diário Oficial da União, Brasília, DF, 27 jan.1999. Define o Sistema Nacional de Vigilância Sanitária, cria a Agência Nacional de Vigilância Sanitária, e dá outras providências. Disponível em: <http://www.planalto.gov.br/ccivil_03/leis/19782.htm>. Acesso em: 5 abr. 2020e.

BRASIL. Câmara dos Deputados. Decreto n ${ }^{\circ}$ 3029, de 16 de abril de 1999. Diário Oficial da União, Brasília, DF, 19 abr.1999. Aprova o Regulamento da Agência Nacional de Vigilância Sanitária, e dá outras providências. Disponível em: <http://www.planalto.gov.br>ccivil_03>decreto>D3029. Acesso em: 5 abr. 2020f. 
BRASIL. Ministério da Saúde. Laboratórios Oficiais. Disponível em: <http://www.saude.gov.br/assistencia-farmaceutica/laboratorios-oficiais>. Acesso em: 5 abr. 2020.

CONTANDRIOPOULOS, André-Pierre. O desafio do acesso a medicamentos em sistemas públicos de saúde. In: BRASIL. Conselho Nacional de Secretários de Saúde. Relatório do Seminário Internacional de Assistência Farmacêutica do CONASS. Brasília, DF: Conselho Nacional de Secretários e Saúde (CONASS), 2010.

GUIADAFARMACIA. Brasil é o sexto maior mercado farmacêutico do mundo. Disponível em: <https://guiadafarmacia.com.br/matéria/ brasil-e-o-setor-mercado-farmaceutico-do-mundo>. Acesso em: 6 abr. 2020.

IBGE. Pesquisa Nacional por Amostra de Domicílios: um panorama da saúde no Brasil, acesso e utilização dos serviços, condições de saúde e fatores de risco e proteção à saúde, Rio de Janeiro, 2008.

JACOB, Cesar Augusto Alckmin. A "reserva do possível”: obrigação de previsão orçamentária e de aplicação da verba. In: GRINOVER, Ada Pellegrini; WATANABE, Kazuo (Org.). O controle jurisdicional das políticas públicas. 2. ed. Rio de Janeiro: Forense, 2013, p. 237284.

LAGO, Carmelo Mesa. O Sistema de Saúde brasileiro: seu impacto na pobreza e na desigualdade. Disponível em: <https://nuso.org/articulo/o-sistema-de-saude-brasileiro-seuimpacto-na-pobreza-e-na-desigualdade/>. Acesso em: 2 abr. 2020.

MOREIRA, Nelson Camatta. Fundamentos de uma teoria da constituição dirigente. Florianópolis: Conceito, 2010.

MOURA, Thaís. Ministério da Saúde suspende 19 medicamentos gratuitos do SUS. Correio Braziliense. Disponível em: <https://www.correiobraziliense. com.br/app/noticia/ciencia-esaude/2019/07/16/interna_ciencia_saude,771353/ ministerio-da-saude-suspende-19medicamentos-gratuitos-do-sus.shtml>. Acesso em: 22 mar. 2020.

NEGRI, Stefania. Saúde e Direito Internacional: algumas reflexões sobre a tardia afirmação de um direito fundamental. Boletim Saúde, Porto Alegre, v. 24, n. 2, p.63-74, jul./dez. 2010.

OLIVEIRA, Gléubia Andrade de; LABRA, Maria Eliana; BERMUDEZ, Jorge. A produção pública de medicamentos no Brasil: uma visão geral. Cadernos de Saúde Pública, Rio de Janeiro, p. 2379-2389, nov. 2006.

ONU. Transformando Nosso Mundo: A Agenda 2030 para o Desenvolvimento Sustentável. Disponível em: <https://nacoesunidas.org/wp-content/uploads/2015/10/agenda2030-ptbr.pdf>. Acesso em: 22 abr.2020.

OPS. Avaliação da assistência farmacêutica no Brasil: estrutura, processo e resultados. Brasília, DF: Ministério da Saúde/Organização Pan-americana de Saúde, 2005.

PACTO GLOBAL. Objetivos de desenvolvimento sustentável (ODS). Disponível em: <https://www.pactoglobal.org.br/ods>. Acesso em: 29 mar.2020. 
POGGE, Thomas. Medicamentos para o mundo: incentivo à inovação sem obstruir o acesso livre. Tradução: Pedro Maia Soares. Revista Internacional de Direitos Humanos, São Paulo, ano 5, n. 8, p. $122-149$, jun. 2008.

SANZ, Consuelo Cuesta. La salud como Derecho Humano. In: LA CALLE, María José de La Fluente y de la Calle; PARDO, Miguel Ángel Montanés; VIÑAS, Antonio Rovira (Coord.). La Declaración Universal de los Derechos Humanos en su 50 aniversario. Barcelona: Boscil, 1998, p. 291-298.

SARLET, Ingo Wolfgang. A eficácia dos direitos fundamentais. Porto Alegre: Livraria do Advogado, 2004.

SARLET, Ingo Wolfgang; FIGUEIREDO, Mariana Filchtiner. Reserva do possível, mínimo existencial e direito à saúde: algumas aproximações. In: SARLET, Ingo Wolfgang; TIMM, Luciano Benett (Org.). Direitos fundamentais: orçamento e reserva do possível. Porto Alegre: Livraria do Advogado, 2010, p. 13-50.

SARMENTO, Daniel. Dignidade da pessoa humana: conteúdo, trajetória e metodologia. Belo Horizonte: Fórum, 2016.

SÉGUIN, Elida. Estatuto da cidade: promessa de inclusão social, justiça social. Rio de Janeiro: Forense, 2002.

TORRES, Ricardo Lobo. O direito ao mínimo existencial. Rio de Janeiro: Renovar, 2009.

WHO. Medicamentos essenciais e tecnologias sanitárias fundamentais no quadro das doenças não transmissíveis: em prol de um conjunto de ações destinadas a melhorar o seu acesso em condições equitativas nos Estados-Membros. Disponível em: $<$ https://www.who.int/nmh/events/essential_medicines_2jul15_portugese.pdf 